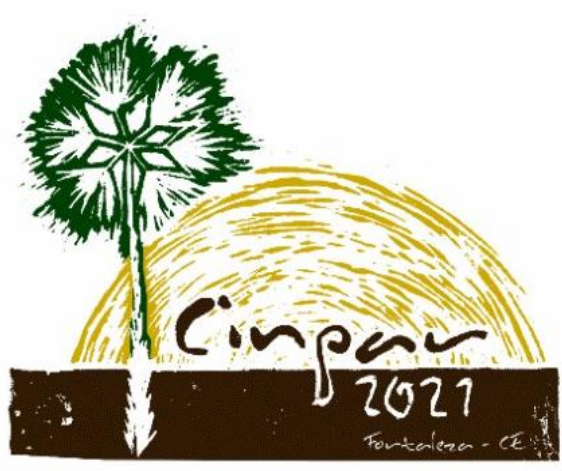

XVII Congresso Internacional sobre Patologia e

Reabilitação das Construções

XVII Congreso Internacional sobre Patología y Rehabilitación de las Construcciones

XVII International Conference on Pathology and Constructions Rehabilitation

FORTALEZA (Brasil), 3 a 5 de junho de 2021

https://doi.org/10.4322/CINPAR.2021.085

\title{
Mapeamento das armaduras expostas em edifício acadêmico e proposta de conduta - Estudo de Caso em Rio Branco (AC)
}

\section{Mapping of exposed steel reinforcement in an academic building and conduct proposal - Case Study in Rio Branco (AC)}

\author{
Kennedy Queiros PESSOA ${ }^{1}$, Kelvin Queiros PESSOA ${ }^{2}$, Gabriela Grotti SILVEIRA ${ }^{3}$ \\ ${ }^{1}$ Universidade Federal do Rio Grande do Sul, Porto Alegre, Brasil, engkennedypessoa@gmail.com \\ ${ }^{2}$ Faculdade Senac Porto Alegre, Porto Alegre, Brasil, engkelvinpessoa@gmail.com \\ ${ }^{3}$ Faculdade UnYleYa, Rio Branco, Brasil, eng.gabrielagrotti@gmail.com
}

\begin{abstract}
Resumo: A degradação de estruturas de concreto armado, decorrentes da corrosão das armaduras, é uma patologia que acomete a construção civil no mundo todo. A corrosão das armaduras é um assunto que não deve passar despercebido durante todas as fases da construção, sendo que o ideal em uma obra é que haja planejamento prévio para que se possa ter um melhor controle tecnológico dos materiais empregados, garantindo assim as melhores condições de aplicação dos mesmos, em especial a utilização de armaduras de aço. Este trabalho teve por objetivo principal mapear os pilares externos com fissuras e que apresentavam armaduras expostas em um edifício educacional na Universidade Federal do Acre - UFAC, sendo que esse prédio conta com atividades educacionais, como salas de aula e de professores, e atendimento médico clínico. Após a realização do estudo de caso, obteve-se, através de ensaio de esclerometria no concreto realizado pela Fundação de Tecnologia do Estado do Acre (FUNTAC), que a resistência do concreto à compressão manteve-se superior à resistência de projeto, $25 \mathrm{MPa}$, para todos os elementos ensaiados. A manifestação patológica mais predominante nos pilares foi a fissuração vertical, aparecendo em 21 dos 58 pilares da edificação. Encontrou-se armaduras exposta com corrosão em 2 pilares do edifício. $O$ diagnóstico apontou como causa das manifestações de corrosão, principalmente, o cobrimento insuficiente, estando abaixo do previsto na ABNT NBR 6118:2014. Outra possível causa apontada para a corrosão foi a má execução do edifício, visto que encontrou-se dificuldade para obtenção de informações da construção. A definição de conduta proposta foi a limpeza das armaduras, com verificação da integridade das seções da mesma, prosseguindo para a aplicação de revestimento anti-corrosão e finalizando com o reparo do componente estrutural, bem como a aplicação de argamassa para regularização do cobrimento mínimo.
\end{abstract}

Palavras-chave: Corrosão das Armaduras. Diagnóstico de Corrosão. Definição de Conduta. Inspeção Predial.

Abstract: The degradation of reinforced concrete structures, resulting from the corrosion of reinforcement, is a pathology that affects civil construction worldwide. The corrosion of reinforcement is a subject that must not go unnoticed during all phases of construction, and the ideal in a work is that there is prior planning so that one can have a better technological control of the materials used, thus guaranteeing the best conditions of application, in particular the use of steel reinforcement. The main objective of this work was to map the external pillars with cracks and exposed armor in an educational building at the Federal University of Acre UFAC, and this building has educational activities, such as classrooms and teachers, and clinical medical care. . After carrying out the case study, it was obtained, through a sclerometry test on concrete carried out by the Technology Foundation of the State of Acre (FUNTAC), that the concrete's resistance to compression remained higher than the design strength, $25 \mathrm{MPa}$, for all the elements tested. The most prevalent pathological manifestation in the pillars was vertical cracking, appearing in 21 of the 58 pillars of the building. 
Armor exposed to corrosion was found in 2 pillars of the building. The diagnosis pointed out as the cause of the corrosion manifestations, mainly, the insufficient covering, being below the predicted in ABNT NBR 6118: 2014. Another possible cause pointed to corrosion was the poor execution of the building, sience it was difficult to obtain construction information. The proposed conduct definition was the cleaning of the reinforcement, with verification of the integrity of its sections, proceeding with the application of anticorrosion coating and ending with the repair of the structural component, as well as the application of mortar to regularize the minimum covering.

Keywords: Pathological Manifestations. Building Inspection. Constructive Systems.

\section{Introdução}

A corrosão das armaduras inseridas no concreto armado é uma preocupação de longa data. Ela tem um impacto avassalador na degradação e deterioração de elementos estruturais e na vida útil da estrutura. Apesar de ser um problema antigo e já bem conhecido, a nossa capacidade de mitigá-la permanece limitada, sendo necessário o desenvolvimento de novas estratégias de mitigação de corrosão funcionalmente mais eficazes para estruturas de concreto armado (BALONIS et. al., 2019).

A corrosão do aço não limita-se apenas à deterioração do desempenho mecânico do concreto, mas também compromete a sua integridade estrutural à medida em que as fissuras e rachaduras desenvolvem-se devido à expansão do volume dos produtos oriundos da corrosão (Ll et. al., 2020).

O Ferro é o principal componente da armadura de aço utilizada na construção civil, reage com o meio ambiente, transformando-se principalmente em Fe2O3 hidratado, conhecido como ferrugem, que apresenta um estado de energia menor e, portanto, mais estável que o do ferro metálico (RIBEIRO et. al., 2018).

A umidade do ar é sem dúvida um dos fatores atmosféricos que implica diretamente na velocidade de corrosão do aço. No entanto, a simples presença de água pura num ar também puro tem baixo potencial de corrosão, ou seja, o processo ocorre lentamente. Entretanto, quando se combina com outros elementos poluentes ou agressivos, passará a ter uma função preponderante no ataque da ferragem (MARCELLI, 2007).

A corrosão conduz à formação de óxidos e hidróxidos de ferro, produtos de corrosão avermelhados, pulverulentos e porosos, chamados de ferrugem, e, conforme Helene (1999) e Ribeiro et. al. (2018), só ocorrem se coexistirem as seguintes condições: a) Existência de um eletrólito; b) Existência de diferença de potencial; c) Existência de oxigênio; e d) Existência de agentes agressivos.

\section{Formas De Identificação Visual}

Helene (1992) resumiu em sua obra as principais características visuais que devemos observar ao vistoriar edificações, sendo essas manifestações típicas divididas em dois itens (Figuras 1 e 2):

Figura 1: Manifestação típica (a)

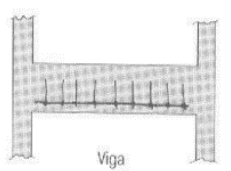

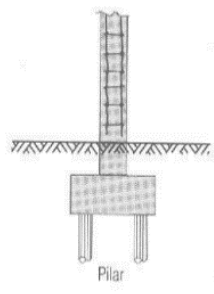

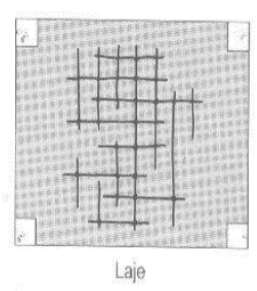

Fonte: HELENE, 1992.
Figura 2: Manifestação típica (b)

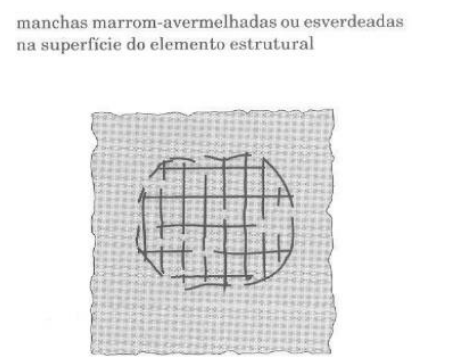

Segundo Helene (1992), na manifestação típica (a) ocorre o aparecimento das armaduras principais e estribos nas vigas e pilares, bem como as armaduras em ambas as direções nas lajes, o que evidencia a ocorrência de desagregação do concreto de cobrimento na região afetada pela corrosão. 
Diagnóstico para a manifestação típica (a) - Figura 1:

1. Concreto com alta permeabilidade e/ou elevada porosidade;

2. Cobrimento insuficiente das armaduras;

3. Má execução.

Sendo as alternativas de correção variáveis conforme o grau de comprometimento da estrutura em função do estado em que a corrosão encontra-se, podendo ser feito reparo, recuperação ou reforço (HELENE, 1992).

Segundo Helene (1992), na manifestação típica (b) ocorre o aparecimento das armaduras nos elementos estruturais, e acompanhadas delas surgem manchas esverdeadas e marrom-avermelhadas na superfície da região afetada.

Diagnóstico para manifestação típica (b) - Figura 2:

1. Agentes agressivos do ambiente impregnados na estrutura (cloretos);

2. Agentes agressivos incorporados involuntariamente ao concreto durante seu amassamento.

Sendo as alternativas de correção variáveis conforme o grau de comprometimento da estrutura em função do estado em que a corrosão encontra-se, podendo ser feito reparo, recuperação ou reforço (HELENE, 1992).

Quando não são observadas as recomendações para projeto, as estruturas de concreto armado estarão sujeitos aos possíveis danos na estrutura, em que o primeiro sintoma é o surgimento das trincas e de manchas marrom-avermelhadas, devidas ao processo inicial de corrosão do aço, que sempre ocorre de forma progressiva através da formação de oxi-hidróxidos de ferro, produtos esses que causam a desagregação de parte do concreto de cobrimento (MARCELLI, 2007).

\section{Metodologia}

Aplicou-se o método genérico de resolução de problemas referentes a patologia proposto por Lichtenstein (1986), para a análise e entendimento dos casos envolvendo corrosão de armaduras em elementos estruturais de concreto armado. O método adotado para a resolução dos casos encontrados é composto por três partes, sendo elas: Parte 1. Levantamento de subsídios; Parte 2. Diagnóstico da situação; Parte 3. Definição de conduta. A metodologia desevolvida neste estudo pode ser observado na figura 3.

Figura 3: Etapas desenvolvidas na realização do estudo.

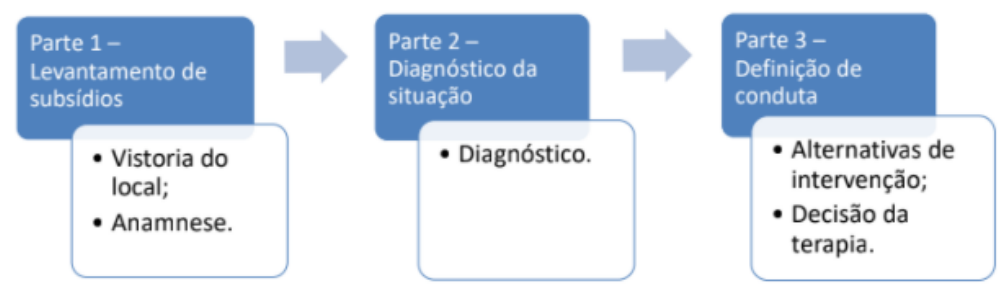

Fonte: adaptado de LICHTENSTEIN, 1986.

\section{Estudo de Caso}

O local para o estudo de caso foi escolhido após observar-se que o mesmo apresentava armaduras expostas em vários elementos estruturais de concreto armado, sendo eles pilares, vigas e lajes. Por ser um edifício que possui função acadêmica e médica, o fluxo de pessoas é considerável, tendo em vista que no local realizamse aulas e consultas, além de serviços administrativos, portanto torna-se pertinente o estudo de caso no edifício quanto a corrosão de suas armaduras, visto que essa é uma patologia com gravidade alta e que pode causar sérios danos ao sistema estrutural do edifício, podendo levar, em casos mais extremos, a ruína do edifício.

O estudo de caso em questão teve seu desenvolvimento realizado em um edifício da Universidade Federal do Acre, na cidade de Rio Branco, capital do estado do Acre. Edifício: Centro de Ciências da Saúde e do Desporto - CCSD; Idade de concretagem: 16 anos. O edifício do CCSD é constituído de salas de aula, 
laboratórios e salas administrativas para os cursos de graduação e pós-graduação pertencentes a esse centro, além de contar com o Setor Médico Pericial, setor este responsável pelas perícias e consultas médicas, e que passou por uma revitalização concluída em 2015. O edifício conta ainda com uma sala administrativa do Serviço Escola de Psicologia. O edifício possui sua estrutura em concreto armado, com dois pavimentos, térreo e superior, tendo destaque o vão livre com pé direito duplo no centro da edificação.

\section{Resultados e Discussões}

A apresentação dos resultados será disposta conforme as etapas do método genérico proposto por Lichtenstein (1986) e apresentado na figura 3.

\subsection{Levantamento de subsídios}

Nesta etapa realizou-se vistorias no local, entrevistas com o Diretor do Centro de Ciências da Saúde e do Desporto e com os Setores de Obras e Manutenção da Prefeitura do Campus, obtendo-se assim o Registro Fotográfico e a Anamnese do local, sendo este último composto pela entrevista com o Diretor do CCSD e o Relatório de Esclerometria do Concreto.

\subsection{1 - Vistoria no Edifício: Registro Fotográfico}

Após vistorias no local, obteve-se o registro fotográfico. Para facilitar o entendimento a Figura 3 representa a posição dos pilares no edifício, bem como suas identificações, estando elas em conformidade com as identificações apresentadas no Relatório de Ensaio № 3380/2019 produzido pela Fundação de Tecnologia do Estado do Acre (FUNTAC).

Na Figura 3 percebemos com facilidade quais pilares apresentam determinada manifestação patológica, e quais foram utilizados no ensaio de esclerometria apresentada no Relatório de Ensaio № 3380/2019 da FUNTAC. Percebe-se também que o edifício possui o total de 58 pilares.

Em todos os pilares observados percebeu-se que a maioria apresenta fissurações próximas as arestas, sendo essas fissurações verticais, semelhantes em comprimento e paralelas as armaduras longitudinais; essas fissurações próximas as arestas por si só já são preocupantes, todavia o grau de gravidade aumenta nas arestas que apresentam fissuração em ambos os lados, pois aumenta as chances de contaminação das armaduras, uma vez que os agentes agressores podem adentrar no concreto por mais de uma entrada.

No edifício observou-se que 21 dos 58 pilares apresentam alguma manifestação patológica, o que corresponde a aproximadamente $36,21 \%$ dos pilares do edifício, sendo os pilares P41, P46 e P56 os mais graves. Pela Figura 3 nota-se que a fissuração e a corrosão apresentam-se, respectivamente, em 36,21\% e $3,45 \%$ dos pilares do edifício; ao comparar as ocorrências de corrosão em relação ao número de pilares que apresentaram fissuração, obtemos que $9,52 \%$ dos pilares com fissuras apresentam armaduras expostas com corrosão. (NOTA: Para a elaboração da Tabela 1, em cada pilar foi contabilizado apenas uma vez cada tipo de manifestação.)

Em nenhuma das armaduras expostas observadas notou-se a presença de perda de seção no aço, todavia essa avaliação não deve ser a final, tendo em vista que na maioria das armaduras expostas havia a presença de produtos de corrosão, o que dificulta a localização de seções danificadas.

\subsection{2 - Anamnese do Edifício: Entrevista com o Diretor do Centro de Ciências da Saúde e do Desporto}

A entrevista foi realizada com o atual diretor do Centro de Ciências da Saúde e do Desporto da Universidade Federal do Acre. Em resposta às perguntas que Ihe foram feitas, o mesmo informou que: O Setor Médico passou por revitalização, entregue em 2015, que em suma objetivou a reorganização do espaço para melhor atender as suas funções; 0 edifício passou por uma reorganização de suas salas devido a necessidade de alocar, temporariamente, o Serviço Escola de Psicologia. O caráter temporário deve-se ao fato de já se encontrar em construção o bloco destinado a receber esse serviço; No período de recesso acadêmico, em dezembro de 2018, houve um vazamento no reservatório superior do edifício, o que ocasionou infiltração. Essa infiltração conseguiu alcançar o pavimento térreo, e causou danos materiais em uma das salas; Em chuvas fortes, ocorre a entrada de água no saguão, todavia com lâmina d'água pequena; Por volta de abril 
de 2019 foi solicitado reparos nos pilares, vigas e lajes do edifício, devido à presença de fissuras, desagregação e armaduras expostas; Há a presença de elementos estruturais com armaduras expostas no edifício a mais de 4 anos, e elas apresentavam em seu início fissuras e estufamento, e, com o passar do tempo, as mesmas progrediram e causaram o desprendimento de parte do concreto de cobrimento.

O diretor informou ainda que o aparecimento dessas armaduras expostas gerou medo e desconfiança em seus usuários, ocorrendo inclusive reclamações de professores quanto à essas manifestações.

\subsection{3 - Anamnese do Edifício: Relatório de Esclerometria do Concreto}

Ensaio Esclerométrico é, de acordo com a ABNT NBR 7584: 2012, o método não destrutivo que mede a dureza superficial do concreto, fornecendo assim elementos para a avaliação da qualidade do concreto endurecido. O ensaio foi executado pela Fundação de Tecnologia do Estado do Acre (FUNTAC) através de seu Laboratório de Concreto e Argamassa. Os serviços de campo foram realizados nos dias 31 de julho e 01 de agosto de 2019, conforme aponta o Relatório de Ensaio № 3380/2019, emitido em 07 de agosto de 2019.

Foram executados 40 ensaios nos pilares, vigas e laje do térreo, com o uso de 16 pontos em cada um. A resistência a compressão do concreto foi obtida por meio do Martelo de Teste de Concreto, com aplicação direta de um impacto sobre a peça de concreto previamente preparado para o ensaio. Os resultados foram calculados com o auxílio do gráfico e da tabela do aparelho. Os elementos ensaiados não sofreram alterações decorrentes do ensaio devido ao mesmo ser enquadrado como Ensaio Não Destrutivo (END).

Metodologia do ensaio: Para a realização desse ensaio, seguiram-se as recomendações e instruções presentes na ABNT NBR 7584: 2012 Concreto endurecido - Avaliação da dureza superficial pelo esclerômetro de reflexão - Método de ensaio, conforme informado no Relatório de Ensaio № 3380/2019.

Resultados do ensaio: Todos os resultados de resistência à compressão obtidos pelo ensaio encontram-se acima da resistência de projeto ( $F c k=25 \mathrm{Mpa}$ ). A margem de dispersão do aparelho, conforme informado no relatório, é de $20 \%$ para mais ou para menos. A posição de aplicação variou entre os elementos ensaiados, sendo usadas as posições 0 ㅇ, 90 으 e 270 , sendo 0 ㅇ a mais utilizada, o martelo para teste de concreto foi o modelo CT -320 A e a data de concretagem está com 16 anos.

Nesse ensaio de esclerometria foram ensaiados 40 elementos estruturais em concreto armado, sendo eles: 26 pilares, 11 vigas e 3 lajes. Através do ensaio, nota-se que todos os valores de resistência à compressão do concreto obtidos foram acima da resistência característica do concreto à compressão (Fck), o que nos diz que o concreto presente nas estruturas está com sua resistência acima da resistência de projeto.

\subsection{Diagnóstico da situação}

\subsection{1 - Resumo dos dados coletados}

A Tabela 1 apresenta o resumo dos quantitativos de ocorrência das manifestações patológicas encontradas nos elementos estruturais que apresentavam algum tipo de dano.

Tabela 1: Resumo das ocorrências de manifestações patológicas em elementos estruturais

\begin{tabular}{|c|c|c|c|}
\hline Elemento Estrutural & \multicolumn{2}{|c|}{ Manifestação Patológica } & Ocorrência \\
\hline \multirow{3}{*}{ Pilares } & \multicolumn{2}{|c|}{ Fissura vertical } & 21 \\
\cline { 2 - 4 } & \multicolumn{2}{|c|}{ Desagregação do concreto } & 4 \\
\cline { 2 - 4 } & \multirow{2}{*}{ Ausência de cobrimento } & Estribo & 2 \\
\cline { 2 - 4 } & \multirow{2}{*}{ Corrosão da armadura } & Armação Principal & 3 \\
\cline { 2 - 4 } & & Estribo & 2 \\
\cline { 2 - 4 } & & Armação Principal & 2 \\
\hline
\end{tabular}

Fonte: Os autores.

Para elaboração da Tabela, em cada elemento estrutural foi contabilizado apenas uma vez cada tipo de manifestação. 


\subsection{2 - Potencial de risco em função das classes de agressividade}

Conforme o apresentado na ABNT NBR 6118: 2014 Projeto de estruturas de concreto - Procedimento, temos:

a) A Classe de Agressividade Ambiental (CAA) do edifício é a II, o que nos diz que a agressividade é moderada, que a classificação geral do tipo de ambiente para efeito de projeto é a Urbana, e, por último, que o risco de deterioração da estrutura é pequeno;

b) O cobrimento nominal, em função da CAA, para lajes, vigas e pilares em concreto armado são, respectivamente: $25 \mathrm{~mm}, 30 \mathrm{~mm}$ e $30 \mathrm{~mm}$;

c) As exigências relativas à fissuração, em função da CAA e do tipo de concreto estrutural, fixam em 0,3 mm o valor máximo de abertura das fissuras, sendo considerado aceitável valores iguais ou inferiores a esse.

Nas fissurações encontradas em diversos elementos estruturais aqui apresentados, constatou-se que a maioria apresenta fissuras com aberturas superiores ao limite, previsto em norma, para estruturas de concreto armado pertencentes a classe de agressividade ambiental II.

\subsection{3 - Cobrimento dos elementos estruturais}

Dentre os elementos que apresentaram ausência do cobrimento, não foi possível a realização da medição do cobrimento na laje. Todavia, após vistorias e medição, concluiu-se que os cobrimentos dos três pilares e da viga estavam abaixo do limite mínimo previsto pela ABNT NBR 6118: 2014 (valor mínimo fixado em $30 \mathrm{~mm}$ ) sendo que os valores de cobrimento obtidos variavam em função do eixo medido. $O$ cobrimento médio encontrado nos 3 pilares foi de $22 \mathrm{~mm}$. Para a viga analisada, observou-se que o cobrimento aproximou-se do recomendado em norma, atingindo $28 \mathrm{~mm}$.

NOTA: todos os valores médios de cobrimento foram obtidos a partir de duas medições em pontos diferentes das armaduras.

Os valores de cobrimento usados como referência para a análise foram extraídos da ABNT NBR 6118: 2014 com versão corrigida em 2014, tendo data de vigência posterior à data de entrega do edifício estudado. Portanto, a versão da norma que foi usada para o dimensionamento do edifício, tendo em visto que o mesmo possui 16 anos de concretagem, foi a ABNT NBR 6118:1980, que previa um cobrimento mínimo para vigas, pilares e arcos variando entre 1,5 a $2,0 \mathrm{~cm}$, conforme a localização do elemento no edifício $(1,5 \mathrm{~cm}$ para elementos no interior do edifício, e $2,0 \mathrm{~cm}$ para elementos ao ar livre).

\subsection{4 - Perda de seção por corrosão}

Nas vistorias não observou-se a ocorrência de armaduras com perda de seção por corrosão, todavia essa avaliação somente deve ser conclusiva após realização de limpeza nas armaduras, para que assim haja um julgamento mais claro quanto a esse assunto, uma vez que os produtos de corrosão dificultam a análise da uniformidade nas seções do aço.

\subsection{5 - Ensaios não destrutivos (Esclerometria em concreto)}

Conforme o Relatório de Ensaio № 3380 da FUNTAC, todos os resultados de resistência à compressão obtidos pelo ensaio encontram-se acima dos $25 \mathrm{MPa}$. Sendo a margem de dispersão do aparelho, conforme informado no relatório, igual a $20 \%$ para mais ou para menos. Pelas Tabelas 4.2 e 4.3 , nota-se que todos os valores de resistência à compressão do concreto obtidos ficaram acima da resistência característica do concreto à compressão (resistência de projeto), o que nos diz que o concreto presente nas estruturas está com sua resistência acima da resistência para a qual foi projetada.

\subsection{6 - Diagnóstico}

A partir dos subsídios levantados e das características visuais das manifestações encontradas nos elementos estruturais de concreto armado, temos que o diagnóstico para essas anomalias são: a) Cobrimento insuficiente das armaduras; b) Má execução; c) Concreto com alta permeabilidade e/ou porosidade (Hipótese). 
O cobrimento abaixo do mínimo previsto em norma contribui para a entrada de agentes agressivos no concreto, como a umidade e o gás oxigênio, o que fornece as condições necessárias a ocorrência da corrosão.

O diagnóstico aponta também a má execução de seu elementos estruturais como uma das possíveis causas para as manifestações de corrosão, sendo desconhecido o nível de controle tecnológico empregado na construção do edifício, ou se houve algum controle de qualidade; desconhece-se também as origens e as condições de estocagem dos materiais empregados na execução do prédio, bem como as técnicas construtivas aplicadas à construção. Esse desconhecimento deve-se ao fato de não se ter obtido todas essas informações junto a PrefCam, sendo a idade da edificação (16 anos) e a má comunicação entre os setores da prefeitura do campus os principais motivos dessa não obtenção de informações.

Esse diagnóstico assinala ainda, como causa da corrosão nas armaduras, a possibilidade do concreto possuir alta permeabilidade e/ou porosidade, hipótese essa que não pode ser testada devido a necessidade de realização de ensaios específicos para determinação dessas características e comparação com o projeto estrutural - que não se teve acesso.

As fissuras encontradas são indícios de corrosão devido a sua forma de apresentação na estrutura, paralelas as armaduras longitudinais e próximas as arestas dos pilares e vigas. A fissuração ocorre devido a tensões internas geradas dentro do elemento de concreto armado, sendo essas tensões internas oriundas dos produtos gerados pela corrosão.

Com a presença de fissuras nos elementos estruturais, ocorre a facilitação de entrada de agentes agressores à estrutura interna do concreto armado, o que potencializa a velocidade de corrosão.

\subsection{7 - Informações complementares}

O diagnóstico apresentado baseia-se nos aspectos visuais manifestados pelas estruturas de concreto armado vistoriadas.

\subsection{Definição de conduta}

A conduta a se seguir foi definida apenas para os elementos de concreto armado que apresentaram armaduras expostas ao ambiente.

Os elemento estruturais que apresentaram armaduras expostas foram: 3 pilares - sendo que em um deles não foi possível a detecção de produtos de corrosão na superfície do aço devido ao mesmo estar pintado. Recomenda-se o tratamento deles devido ao caráter evolutivo que a corrosão das armaduras possui, tendo em vista que a exposição das armaduras ao ambiente deixam-nas vulneráveis a mais agentes agressivos, o que pode acarretar a potencialização da velocidade de corrosão, bem como o aumento da área de corrosão e a perda de concreto na estrutura; somado a isso há a possibilidade de, com a evolução da corrosão, ocorrer perda de seção nas armaduras principais e estribos, o que causa sérios danos ao concreto armado, comprometendo, dependendo do nível da perda, a segurança estrutural do edifício.

\subsection{1 - Conduta proposta}

Conforme Helene (1992), recomenda-se os seguintes procedimentos:

a) Remoção cuidadosa do concreto afetado e dos produtos de corrosão, limpando-se bem as superfícies e utilizando-se escova de aço para a limpeza das armaduras corroídas;

b) Analisar as armaduras após a limpeza para verificação da necessidade de reconstituição da seção original da armadura ou aplicação de armadura suplementar;

c) Aplicação de revestimento de proteção - como pintura com tinta inibidora de corrosão - nas armaduras tratadas e nas suplementares (caso sejam necessárias);

d) Recuperação do componente estrutural, mantendo-se as dimensões originais, podendo-se utilizar: Argamassa polimérica base cimento; Argamassa base epóxi; Argamassa base poliéster.

Eventualmente deve-se aplicar argamassa em todas as superfícies para aumentar o cobrimento e proteger o componente estrutural, de modo que se atinja a espessura mínima de cobrimento recomendada na ABNT NBR 6118: 2014. 


\section{Considerações Finais}

- Dos 58 pilares presentes no edifício estudado, 21 estavam com fissurações verticais nas faces, com proximidade as arestas, manifestação característica de corrosão, devido a expansão do volume de seus produtos;

- Dentre os 21 pilares, 3 estavam com armaduras expostas, e das 3 com a exposição do aço, 2 apresentavam produtos de corrosão na superfície do metal. Encontrou-se dificuldade na identificação da corrosão em um dos 3 pilares com armaduras expostas devido ao mesmo estar pintado;

- A presença de fissuras nos elementos estruturais, ocorre a facilitação de entrada de agentes agressores à estrutura interna do concreto armado, o que potencializa a velocidade de corrosão;

- A medição do cobrimento nas armaduras apontou que ele encontrava-se abaixo do recomendado em norma regulamentadora vigente, todavia dentro das prescrições normativas vigentes na época em que o edifício foi construído;

- O ensaio de esclerometria em concreto aplicado nos pilares, vigas e lajes do edifício, indicou que todos os elementos estruturais de concreto armado ensaiados possuem resistência à compressão do concreto acima da resistência de projeto (Fck = $25 \mathrm{Mpa}$ );

- Em entrevista aplicada ao diretor em exercício do edifício, descobriu-se que as armaduras estão nessa condição de exposição há 4 anos.

- O diagnóstico apontou como causa da corrosão o cobrimento insuficiente e a possível má execução da obra, hipótese essa levantada devido à ausência de informações a respeito da construção do edifício.

- A definição de conduta proposta foi a limpeza das armaduras para verificar se houve perda de seção nelas, prosseguindo-se à aplicação de proteção na armadura e a recuperação do componente estrutural.

\section{Referências Bibliográficas}

Associação Brasileira De Normas Técnicas - ABNT. (2014). NBR 6118 - Projeto de estruturas de concreto Procedimento. Rio de Janeiro, 2014.

. (1980). NBR 6118 - Projeto e execução de obras de concreto armado. Rio de Janeiro, 1980.

. (2012). NBR 7584 - Concreto endurecido - Avaliação da dureza superficial pelo esclerômetro de reflexão - Método de ensaio. Rio de Janeiro, 2012.

BALONIS, Magdalena; SANT, Gaurav; ISGOR, O. Burkan. Mitigating steel corrosion in reinforced concrete using functional coatings, corrosion inhibitors, and atomistic simulations. Cement and Concrete Composites, v. 101, p. 15-23, 2019.

Helene, P. R. L. (1992). Manual para Reparo, Reforço e Proteção de Estruturas de Concreto. 2a ed. São Paulo: Pini, 1992.

LI, Chenzhi; JIANG, Linhua; LI, Shanshan. Effect of limestone powder addition on threshold chloride concentration for steel corrosion in reinforced concrete. Cement and Concrete Research, v. 131, p. $106018,2020$.

Lichtenstein, N. B. (1986). Patologia das Construções - Procedimentos para diagnóstico e recuperação. Boletim Técnico 06/86 - Departamento de Engenharia de Construção Civil da Escola Politécnica da Universidade de São Paulo, São Paulo, 1986.

Marcelli, M. (2007). Sinistros na Construção Civil. 1ạ ed. São Paulo: Pini, 2007.

Ribeiro, D. V., et. al. (2018). Corrosão e Degradação em Estruturas de Concreto: Teoria, Controle e Técnicas de Análise e Intervenção. 2aㅡ ed. Rio de Janeiro: Elsevier, 2018. 